\title{
Validity of uniaxial accelerometry during activities of daily living in children
}

Accepted: 9 September 2003 / Published online: 21 October 2003

(C) Springer-Verlag 2003

\begin{abstract}
The purpose of this study was to examine the validity of treadmill-based equations of two commonly used uniaxial accelerometers to estimate energy expenditure (EE) during activities of daily living in children. Twelve subjects with mean (SD) age11.4 (0.4) years engaged in a choreographed routine consisting of three activities (sweeping, bowling, and basketball) of $4 \mathrm{~min}$ duration while wearing a Manufacturing Technology, Inc. (MTI) accelerometer, Caltrac accelerometer, and a portable gas analyzer $\left(\right.$ Cosmed $\left.\mathrm{K} 4 \mathrm{~b}^{2}\right)$. The equations of Trost et al. and Sallis et al. were used to convert activity counts to estimations of EE for the MTI and Caltrac, respectively. Correlation coefficients between Caltrac predictions of EE and measured EE from indirect calorimetry ranged from $r=0.22$ to 0.72 for individual activities. Correlations between MTI EE predictions and indirect calorimetry ranged from $r=0.50$ to 0.68 for individual activities. When the activities were pooled the correlations between EE from uniaxial accelerometers and EE from indirect calorimetry were moderately strong (MTI, $r=0.78$ and Caltrac, $r=0.82$ ). Interaccelerometer (counts $\mathrm{min}^{-1}$ ) correlations were 0.08 , $-0.54,0.63$, and 0.79 for sweeping, bowling, basketball, and pooled data, respectively. The overall mean difference, or bias, and $95 \%$ confidence intervals (CI) for each uniaxial accelerometer compared to indirect calorimetry were as follows: Caltrac, bias $=2.80(2.36,3.24) \mathrm{kcal}$ $\min ^{-1}$; MTI, bias $=0.88(0.23,1.53) \mathrm{kcal} \min ^{-1}$. Both accelerometers significantly underestimated measured
\end{abstract}

J. C. Eisenmann $(\bowtie)$

Department of Health and Human

Performance, Iowa State University,

255 Forker Building, Ames, IA 50011, USA

E-mail: jce@iastate.edu

Tel.: + 1-515-2948755

Fax: + 1-515-2948740

S. J. Strath

University of Michigan, Ann Arbor, Michigan, USA

D. Shadrick · P. Rigsby · N. Hirsch · L. Jacobson University of Wyoming, Laramie, Wyoming, USA
EE $(P<0.05)$. Uniaxial accelerometers provide potential for the measurement of physical activity (PA) and EE in children. Future studies refining accelerometry predictions of PA and EE are warranted.

Keywords Motion sensors · Energy expenditure · Physical activity $\cdot$ Validity

\section{Introduction}

The measurement of physical activity (PA) and energy expenditure (EE) is important in the PA sciences. Despite the recognition of the importance of habitual PA on health (U.S. Department of Health and Human Services 1996), methodological issues regarding the measurement of PA and EE require further examination (Montoye 2000), particularly in children. Identifying a reliable, valid, and feasible PA measurement tool in children is important given the early origins of obesity (Power et al. 1997), cardiovascular disease (Berenson et al. 1998), and osteoporosis (Bailey et al. 1996) and the potential role of childhood physical activity on chronic disease risk factors (Casperson et al. 1998).

Results from the 1998 Canadian National Population Health Survey showed that $55 \%$ of $12-$ to 19 -yearold boys and $65 \%$ of 12 - to 19-year-old girls did not meet the recommended levels of PA $\left(3 \mathrm{kcal} \cdot \mathrm{kg}^{-1} \cdot \mathrm{day}^{-1}\right)$ (Eisenmann et al., in review). However, these PA prevalence estimates are based on self-reported participation in 19 different physical activities. Given the limitation of self-reported PA (cognitive abilities to recall PA, sporadic movement patterns) (Sallis and Saelens 2000), particularly low-to-moderate intensity activity, objective measurements are necessary to accurately monitor PA levels and estimate EE in children and adolescents.

Currently, there is considerable interest in the utility of electronic devices to determine the PA patterns and 
EE of children (Trost 2001). Although validation studies have compared electronic devices with oxygen consumption $\left(V \mathrm{O}_{2}\right)$ during treadmill walking or running (Bray et al. 1992; Eston et al. 1998; Freedson et al. 1997; Louie et al. 1999; Maliszewski et al. 1991; Sallis et al. 1990; Trost et al. 1998), few have examined this relationship during free-living activity in children (Eston et al. 1998; Louie et al. 1999). In addition, current equations to predict energy expenditure are based upon treadmill walking and running in controlled, laboratory environment (Sallis et al. 1990; Trost et al. 1998). Therefore, the purpose of this study was to examine the validity of treadmill-based equations of two commonly used uniaxial accelerometers to estimate EE during activities of daily living in children.

\section{Methods}

\section{Subjects}

Subjects included 12 (7 boys, 5 girls) children. The mean (SD) of the sample for age, stature, and body mass were 11.4 (0.4) years, $147.2(9.1) \mathrm{cm}$, and $42.3(7.5) \mathrm{kg}$, respectively. A written consent and assent form were signed by the parent/guardian and child, respectively, prior to participating in the study. The study was approved by the University of Wyoming Institutional Review Board on Human Subjects and complies with the Declaration of Helsinki.

Procedures

Each subject performed a choreographed routine consisting of three activities (sweeping, bowling, and basketball) of $4 \mathrm{~min}$ duration. For the activities, subjects were given some guidelines on the task but were given freedom to perform the activities at their normal or preferred speed. During the routine, the activity levels of the subjects were assessed concurrently with two uniaxial accelerometers, one from Manufacturing Technology, Inc. (MTI, Fort Walton Beach, Fla.) and a Caltrac (Hemokinetics, Inc., Madison, Wis.), a heart rate (HR) monitor (Polar Electro, Tampere, Finland) and a portable gas analysis system (Cosmed $\mathrm{K} 4 \mathrm{~b}^{2}$, Cosmed, Rome, Italy). The accelerometers were attached snugly to the hip by an elastic waist belt or directly to clothing. The MTI and Caltrac were positioned on the left and right sides of the hip at the midaxillary line, respectively. The accelerometers and Cosmed $\mathrm{K} 4 \mathrm{~b}^{2}$ were synchronized to begin data collection utilizing an external timepiece.

\section{Indirect calorimetry}

The Cosmed $\mathrm{K} 4 \mathrm{~b}^{2}$ is a telemetric measurement system composed of a soft, flexible face mask (Hans Rudolph, Kansas City, Mo.) to sample expired air, and a sensor system to measure ventilation and oxygen $\left(\mathrm{O}_{2}\right)$ and carbon dioxide $\left(\mathrm{CO}_{2}\right)$ concentrations in the expired air. The sensor unit is a small analyzer that is fixed onto a chest harness worn by the subject. The Cosmed $\mathrm{K}_{4} \mathrm{~b}^{2} \mathrm{O}_{2}$ and $\mathrm{CO}_{2}$ analyzers were calibrated prior to each test session according to the manufacturer's guidelines. After data collection, the apparatus was interfaced with a computer to download all recorded parameters into a software package from the manufacturer. The validity of the Cosmed $\mathrm{K}_{4} \mathrm{~b}^{2}$ has been shown by our group (Eisenmann et al. 2003) and others (McLaughlin et al. 2001) in adults.
Uniaxial accelerometry

The MTI accelerometer, formerly made by Computer Science and Applications, Inc. (CSA, Shalimar, Fla.) is a small $(5 \times 4 \times 1.5 \mathrm{~cm})$, lightweight (43 g) unit with a time-sampling mechanism that uses a cantilevered piezoelectric plate to sense acceleration in the vertical plane. An analog to digital filter generates a linear output from the acceleration value. This output is then summed over a specified time interval. The unit was programmed to store data at 1 -min epochs. The Caltrac is a small $(7 \times 7 \times 2 \mathrm{~cm})$, lightweight device that measures both the quantity and intensity of movement in the vertical plane. The internal program of the Caltrac can estimate EE by summing the predicted resting metabolic rate (RMR) and energy cost of activity. The RMR, which accounts for a majority of daily $\mathrm{EE}$, is predicted based on adult equations; therefore, the internal program was overridden by setting the following values as suggested by Sallis et al. (1990): age $=99$, gender $=0$, weight $=25$, height $=36$.

\section{Data analysis}

Data from the Cosmed $\mathrm{K} 4 \mathrm{~b}^{2}$ were averaged over 1-min intervals and oxygen consumption/EE values were averaged from min 2 to 4 for each task. To account for the added mass of the Cosmed $\mathrm{K} 4 \mathrm{~b}^{2}, 1 \mathrm{~kg}$ was added to the measured body mass in all calculations. Data from the MTI was downloaded following the routine. The average counts per minute were determined over the same time frame as the $V \mathrm{O}_{2}$ values and converted to estimated EE by the equation of Trost et al. (1998): $\mathrm{EE}\left(\mathrm{kcal} \mathrm{min}^{-1}\right)=-2.23+0.0008(-$ counts min $\left.^{-1}\right)+0.08$ (body mass, $\mathrm{kg}$ ).

The Caltrac provided an activity count that can also be converted to EE when multiplied by $0.101 \mathrm{kcal} \mathrm{kg}^{-1}$ per activity count (Sallis et al. 1990). The activity counts were recorded following each task and divided by four to provide a rate per minute (i.e., counts $\min ^{-1}$ ).

\section{Statistical analysis}

Descriptive statistics were calculated for each PA measure for each task. Pearson correlation coefficients were computed to depict the strength of the relationship between variables. Given the limitations of expressing the validity of measurements by the Pearson correlation coefficient (3), the Bland-Altman procedure was used to examine the pairwise comparison between EE $\left(\mathrm{kcal} \cdot \mathrm{min}^{-1}\right)$ measured by the uniaxial accelerometers and indirect calorimetry. Error scores were computed by subtracting the estimate (accelerometers) from the criterion (indirect calorimetry). A onesample $t$-test was performed to examine if the mean error scores were significantly different from zero. Error scores were graphically illustrated according to the procedures of Bland and Altman (1986). Briefly, this was done by plotting the error scores for EE (e.g., indirect calorimetry minus MTI) $\left(\mathrm{kcal}^{\prime} \mathrm{min}^{-1}\right)$ for each subject against the mean value of the two respective methods [e.g., (MTI + indirect calorimetry)/2]. The mean error scores were illustrated by a solid horizontal line and the limits of agreement $( \pm 2$ SD from the mean) were shown as dashed horizontal lines. Statistical analyses were conducted using SPSS version 11.0.

\section{Results}

Table 1 shows the descriptive values obtained from accelerometry and indirect calorimetry for each task. Physiological and accelerometry output data were stratified from lowest to highest across sweeping, bowling, and basketball. The variability represented by the range of values within each task should be noted. 
Table 1 Physiological and mechanical responses to lifestyle activities in children. Values given are mean (SD) and range

\begin{tabular}{|c|c|c|c|}
\hline & Sweeping & Bowling & Basketball \\
\hline \multirow[t]{2}{*}{ HR (beats' $\min ^{-1}$ ) } & $126.9(13.6)$ & $138.8(14.7)$ & $187.8(18.2)$ \\
\hline & $103-153$ & $123-174$ & $144-212$ \\
\hline \multirow[t]{2}{*}{$\dot{V} \mathrm{O}_{2}\left(\mathrm{ml}^{\cdot} \mathrm{kg}^{-1} \mathrm{~min}^{-1}\right)$} & $15.9(3.1)$ & $21.6(3.4)$ & $36.2(5.5)$ \\
\hline & $11.5-22.4$ & $16.6-28.2$ & $25.1-45.0$ \\
\hline \multirow[t]{2}{*}{ Caltrac (counts' $\min ^{-1}$ ) } & $0.1(0.2)$ & $0.4(0.2)$ & $1.0(0.5)$ \\
\hline & $0-0.5$ & $0.25-0.75$ & $0.25-1.75$ \\
\hline MTI (counts' $\min ^{-1}$ ) & $965.2(450.7)$ & $2824.9(724.3)$ & $7282.3(4682.4)$ \\
\hline \multicolumn{4}{|l|}{$\mathrm{EE}\left(\mathrm{kcal}^{\prime} \mathrm{min}^{-1}\right)$} \\
\hline \multirow[t]{2}{*}{ Indirect calorimetry } & $3.2(0.7)$ & $4.4(0.8)$ & $7.4(2.0)$ \\
\hline & $1.6-4.4$ & $3.2-5.5$ & $4.9-10.9$ \\
\hline \multirow[t]{2}{*}{ Caltrac $^{\mathrm{a}}$} & $0.5(0.7)$ & $1.7(0.7)$ & $4.3(2.4)$ \\
\hline & $0-1.8$ & $0.9-2.9$ & $1.1-8.2$ \\
\hline \multirow[t]{2}{*}{$\mathrm{MTI}^{\mathrm{b}}$} & $1.9(0.8)$ & $3.4(0.9)$ & $7.0(3.7)$ \\
\hline & $0.4-3.1$ & $1.6-4.4$ & $2.8-15.4$ \\
\hline
\end{tabular}

a Calculated from the equation of Sallis et al.

${ }^{b}$ Calculated from the equation of Trost et al.

Table 2 Pearson correlations coefficients between indirect calorimetry $\left(\mathrm{kcal} \cdot \mathrm{min}^{-1}\right)$ and accelerometers $\left(\mathrm{kcal} \cdot \mathrm{min}^{-1}\right)$ during three activities in children

Indirect calorimetry

\begin{tabular}{ll}
\hline Sweeping & \\
MTI & $0.58^{*}$ \\
Caltrac & $0.72^{*}$ \\
Bowling & \\
MTI & $0.68^{*}$ \\
Caltrac & 0.22 \\
Basketball & \\
MTI & 0.50 \\
Caltrac & $0.59^{*}$ \\
Pooled & $0.78^{*}$ \\
MTI & $0.82^{*}$ \\
Caltrac & \\
$* P<0.05$ &
\end{tabular}

Table 2 shows the Pearson correlation coefficients between accelerometry and physiological responses. Except for the correlation between Caltrac EE and indirect calorimetry EE for bowling $(r=0.22)$, the correlations between accelerometry and indirect calorimetry ranged from 0.50 to 0.72 for individual activities. When the activities were pooled the correlations between $\mathrm{EE}$ from uniaxial accelerometers and EE from indirect calorimetry $(r=0.78$, MTI and $r=0.82$, Caltrac) were moderate to strong. Inter-accelerometer (counts $\mathrm{min}^{-1}$ ) correlations were $0.08,-0.54,0.63$, and 0.79 for sweeping, bowling, basketball, and pooled data, respectively.

Bland-Altman plots are shown in Fig. 1. The overall mean difference, or bias, and 95\% confidence intervals for each uniaxial accelerometer were as follows: Caltrac, bias $=2.80(2.36,3.24) \mathrm{kcal} \cdot \mathrm{min}^{-1} ;$ MTI, bias $=0.88$ $(0.23,1.53) \mathrm{kcal} \cdot \mathrm{min}^{-1}$. Both accelerometers significantly underestimated measured EE $(P<0.05)$.

\section{Discussion}

Given the limitations of self-reported PA and the interest in quantifying it in children, the use of objective measures of PA, particularly uniaxial accelerometers has gained considerable interest (Trost 2001). In this study, the validity of the MTI and Caltrac to estimate EE during different activities of daily living were examined. Results indicated moderate to strong correlations between EE derived from published regression equations based on activity counts in two widely used unixial accelerometers compared with indirect calorimetry.

Previous studies have shown moderate to high correlations $(r=0.70-0.90)$ between accelerometer activity counts and indirect calorimetry during treadmill walking and running (Bray et al. 1992; Eston et al. 1998; Freedson et al. 1997; Louie et al. 1999; Maliszewski et al. 1991; Sallis et al. 1990; Trost et al. 1998). Few studies have examined the validity of accelerometers during activities that represent daily living (i.e., non-treadmill). In two studies by Eston and colleagues (Eston et al. 1998; Louie et al. 1999) correlations between MTI activity counts and scaled $V \mathrm{O}_{2}\left(\mathrm{ml} \cdot \mathrm{kg}^{-0.75} \mathrm{~min}^{-1}\right)$ during crayoning, catching, and hopscotch were high $(r=0.85-$ 0.88). Similar results have also been found for the MTI during lifestyle activities in adults (Bassett et al. 2000; Hendelman et al. 2000; Welk et al. 2000). Others have compared the MTI and Caltrac accelerometers with doubly labeled water (DLW) or whole-room calorimetry. Johnson et al. (1998) found a weak, inverse correlation $(r=-0.09)$ between Caltrac activity counts and activity EE derived from DLW. When EE was derived from the Sallis et al. equation, it significantly overestimated activity EE (956 vs $469 \mathrm{kcal}^{-1 a y^{-1}}$ ). In a similar study, correlations between MTI activity counts and activity EE derived from DLW were moderate $(r=0.39$ 0.58) (Ekelund et al. 2001). The correlations improved when gender and body mass were partitioned out, which was most likely due to the influence of these two variables on EE. In the only study to date to compare the MTI with whole-room calorimetry, correlations were moderately strong $(0.73)$ during $6 \mathrm{~h}$ in which children performed structured activities (Puyua et al. 2002). The authors also developed threshold counts for the MTI. Based on our mean activity count data, sweeping and bowling would be classified as moderately light ( $>800$ and $<3,200)$ while basketball would be classified as moderate intensity activity $(>3,200$ and $<8,200)$. The $\mathrm{HR}$ and $V \mathrm{O}_{2}$ data from these activities also coincide with the respective classifications of intensity.

Uniaxial accelerometers and the published treadmillbased equations to estimate EE are not without limitations. In this study they tended to underestimate the energy cost of activity. This is perhaps explained by the inability to measure upper body movement during the activities examined here. However, the addition of the MTI wrist counts adds little to the estimation of EE in adults (Swartz et al. 2000). Whether this holds true in 
Fig. 1 Bland-Altman plots depicting error scores (indirect calorimentry minus device) for the a Caltrac and b MTI accelerometers. The solid line represents the mean error, and the dashed lines represent the upper and lower limits of agreement
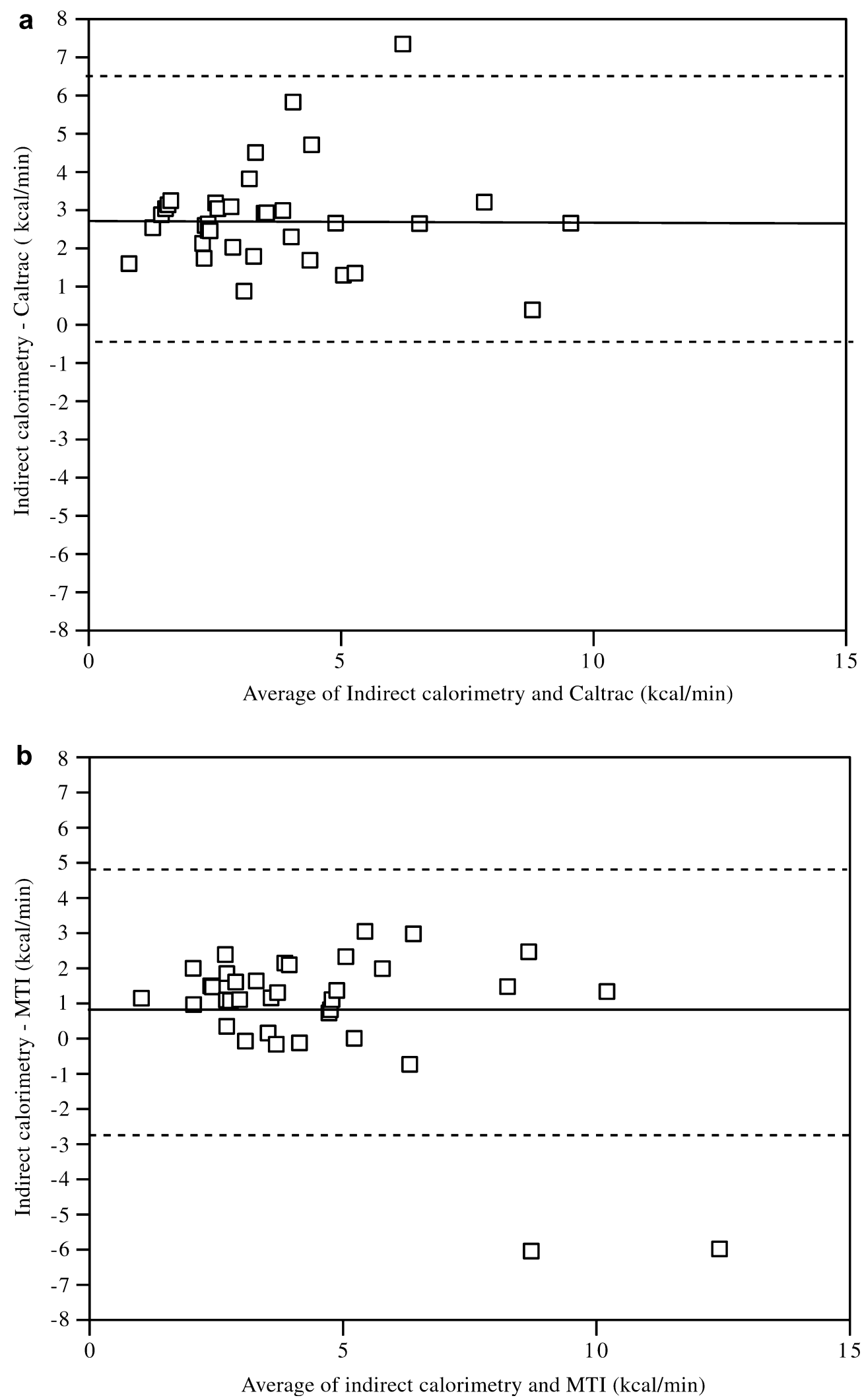

children remains to be examined. It has been proposed that using accelerometry data in combination with HR data can significantly improve the prediction of EE (Strath et al. 2001, 2002). In children, the addition of
HR to motion sensor devices (pedometer, uniaxial and triaxial accelerometers) increased the prediction of scaled $\mathrm{VO}_{2}$ (Eston et al. 1998). The efficacy of using a combined HR-motion sensor approach warrants further 
exploration as a technique to estimate free-living activity in children.

The equations used to derive EE from activity counts for children were developed from treadmill walking and running (Sallis et al. 1990; Trost et al. 1998). Our data show that the equations underestimate EE for free-living activities by about $1-3 \mathrm{kcal} \cdot \mathrm{min}^{-1}$. It remains to be determined if these regression equations are appropriate for other free-living activities in children. We suggest that more activities based on treadmill walking and running and a variety of free-living activities need to be evaluated in a larger sample size in order to develop a comprehensive regression equation to estimate EE using accelerometers. Despite the limitations, uniaxial accelerometers have the ability to objectively capture concurrent PA and EE levels in children as shown here and in other studies (Eston et al. 1998; Puyua et al. 2002; Trost et al. 1998). In addition, the MTI has the ability to store data for prolonged periods and provide detailed information on the frequency, intensity and duration of PA. Given the current interest in PA and health-related fitness of children, the need for objective tools to monitor PA and EE levels is clearly warranted.

In conclusion, the present study found a moderate to strong correlation between EE determined from published regression equations for uniaxial accelerometers and indirect calorimetry during activities of daily living in a small sample of children. However, the validity of the accelerometers varied by activity, which highlights some of the limitations associated with accelerometry and the published laboratory-based equations. Nonetheless, the results agree with previous studies in children and adults that accelerometers offer potential in the measurement of $\mathrm{PA}$ and EE. Future work aimed at refining accelerometry predictions of PA and EE is warranted.

Acknowledgement This study was funded by a College of Health Sciences Summer Seed Grant from the University of Wyoming awarded to Dr. Joey C. Eisenmann.

\section{References}

Bailey DA, Faulkner RA, McKay HA (1996) Growth, physical activity, and bone mineral acquisition. Exerc Sport Sci Rev 24:233-266

Bassett DR, Ainsworth BE, Swartz AM, Strath SJ, O'Brien WL, King GA (2000) Validity of four motion sensors in measuring moderate intensity physical activity. Med Sci Sports Exerc 32 [Suppl]:S471-S480

Berenson GS, Srinivasan SR, Bao W, Newman WP, Tracy RE, Wattigney WA (1998) Association between multiple cardiovascular risk factors and atherosclerosis in children and young adults. N Engl J Med 338:1650-1656

Bland JM, Altman DG (1986) Statistical methods for assessing agreement between two methods of clinical measurement. Lancet I:307-310

Bray MS, Morrow JR, Pivarnik JM, Bricker JT (1992) Caltrac validity for estimating energy expenditure with children. Pediatr Exerc Sci 4:166-179

Casperson CJ, Nixon PA, DuRant RH (1998) Physical activity epidemiology applied to children and adolescents. Exerc Sport Sci Rev 26:341-403
Eisenmann JC, Brisko N, Shadrick D, Welsh S (2003) Comparative analysis of the Cosmed Quark b2 and K4b2 gas analysis systems. J Sports Med Phys Fit 43:150-155

Ekelund U, Sjostrom M, Yngve A, Poorvliet E, Nilsson A, Froberg K, Wedderkopp N, Westerterp K (2001) Physical activity assessed by activity monitor and doubly labeled water in children. Med Sci Sports Exerc 33:275-281

Eston RG, Rowlands AV, Ingledew DK (1998) Validity of heart rate, pedometry, and accelerometry for predicting the energy cost of children's activities. J Appl Physiol 84:362-371

Freedson PS, Sirard J, Debold N (1997) Validity of two physical activity monitors in children and adolescents. In: Welsman JR (ed) Children and exercise XIX. Spon, London, pp 127-131

Hendelman D, Miller K, Baggett C, Debold E, Freedson P (2000) Validity of accelerometry for the assessment of moderate intensity physical activity in the field. Med Sci Sports Exerc 32 [Suppl]:S442-S449

Johnson RK, Russ J, Goran MI (1998) Physical activity related energy expenditure in children by doubly labeled water as compared with the Caltrac accelerometer. Int $\mathbf{J}$ Obes Relat Metab Disord 22:1046-1052

Louie L, Eston RG, Rowlands AV, Keung Tong K, Ingledew DK, Fu FH (1999) Validity of heart rate, pedometry, and accelerometry for estimating the energy cost of activity in Hong Kong Chinese boys. Pediatr Exerc Sci 11:229-239

Maliszewski AF, Freedson PS, Ebbeling CJ, Crussemeyer J, Kastango KB (1991) Validity of the Caltrac accelerometer in estimating energy expenditure and activity in children and adults. Pediatr Exerc Sci 3:141-151

McLaughlin JE, King GA, Howley ET, Bassett DR, Ainsworth BA (2001) Validation of the Cosmed K4b2 portable metabolic system. Int J Sports Med 22:280-284

Montoye HJ (2000) Introduction: evaluation of some measurements of physical activity and energy expenditure. Med Sci Sports Exerc 32:S439-S441

Power C, Lake JK, Cole TJ (1997) Measurement and long-term health risks of child and adolescent fatness. Int $\mathbf{J}$ Obes Relat Metab Disord 21:507-526

Puyua MR, Adolph AL, Vohra FA, Butte NF (2002) Validation and calibration of physical activity monitors in children. Obes Res 10:150-157

Sallis JF, Saelens BE (2000) Assessment of physical activity by selfreport: status, limitations, and future directions. Res Q Exerc Sport 71:1-14

Sallis JF, Buono MJ, Roby JJ, Carlson D, Neson JA (1990) The Caltrac accelerometer as a physical activity monitor for schoolage children. Med Sci Sports Exerc 22:698-703

Strath SJ, Bassett DR Jr, Swartz AM, Thompson DL (2001) Simultaneous heart rate-motion sensor technique to estimate energy expenditure. Med Sci Sports Exerc 33:2118-2123

Strath SJ, Bassett DR, Jr, Thompson DL, Swartz AM (2002) Validity of the simultaneous heart rate-motion sensor technique for measuring energy expenditure. Med Sci Sports Exerc 34:888-894

Swartz AM, Strath SJ, Bassett DR, O'Brien WL, King GA, Ainsworth BE (2000) Estimation of energy expenditure using CSA accelerometers at hip and wrist sites. Med Sci Sports Exerc 32 [Suppl]:S450-456

Trost SG (2001) Objective measurement of physical activity in youth: current issues, future directions. Exerc Sport Sci Rev 29:32-36

Trost SG, Ward DS, Moorehead SM, Watson PD, Riner W, Burke JR (1998) Validity of the computer science and applications (CSA) activity monitor in children. Med Sci Sports Exerc 30:629-633

U.S. Department of Health and Human Services (1996) Physical Activity and Health: a report of the surgeon general. U.S. Department of Health and Human Services, Centers for Disease Control and Prevention, National Center for Chronic Disease Prevention, Atlanta, Ga.

Welk GJ, Blair SN, Wood K, Jones S, Thompson RW (2000) A comparative evaluation of three accelerometry-based physical activity monitors. Med Sci Sports Exerc 32:S489-S497 